www.jmscr.igmpublication.org

Index Copernicus Value: 79.54

ISSN (e)-2347-176x ISSN (p) 2455-0450

crossrefDOI: https://dx.doi.org/10.18535/jmscr/v7i2.158

\title{
A Study on Pre-Hospital and in Hospital Factors Affecting Thrmobolysis in ST Segment Elevation Myocardial Infarction (STEMI) from Tertiary Care Centre in South India
}

\author{
Authors \\ Dr Dhiraj Ramdas Jadhav, Dr Vinay R Pandit
}

\section{Introduction}

Worldwide, cardiovascular disease (CVD) accounts for 17.5 million deaths and $46.2 \%$ of all deaths due to Non Communicable Diseases. The majority of deaths occur in low income countries such as India. ${ }^{1}$ Around 29.8 million coronary artery disease patients are in India. South Indians are at higher risk of mortality from CVD. ${ }^{2}$ The Global Burden of Diseases study highlighted that in India, mortality from Acute Coronary Syndrome [ACS] is projected to increase from 1.6 million in 2000 to approximately 64 million by $2015 .^{3}$

Delay in presentation are attributed mostly to the patient's own decisions, and other factors contributing to delay are age, gender, education, marital status, living conditions, lack of transport facility, lack of perception of symptoms. These factors are influenced by socio-economic factors and vary from region to region. However, patient delay time, which accounts for $75 \%$ of the total pre-hospital delay has not changed in the past decade. Thus, reducing patient delay time and taking care of factors responsible for delay, is very crucial for better outcome. ${ }^{4-7}$

\section{Methods}

A prospective observational study was conducted at department of emergency medicine, in a tertiary care teaching hospital, from South India. The objective of the study was to identify the prehospital and in-hospital factors associated with the thrombolytic therapy in STEMI. All patients attending emergency department with symptoms suggestive of AMI and ECG showing STEMI were included in the study. The study was conducted from July 2014 to June 2016. A total of 413 patients were enrolled. Data was collected in structured format with reference to demographic features, initial symptoms, prehospital measures received, mode of transport and risk factors. Symptoms-to-door, door-to-diagnosis and door to needle time were estimated. The cases were divided into two groups based on thrombolytic therapy received or not. Various factors affecting thrmobolysis were analyzed. The prehospital factors analyzed were- lack of identification symptoms, neglected and atypical symptoms, consultation at local hospital, missed diagnosis, transport related factors. In hospital factors analyzed were door to ECG time, interpretation of ECG, consultation with cardiologist for initiation of thrmobolysis. All the data was entered in 
Epidata version 3.1 and analyzed by Epidata Analysis version 2.2.2.183.

\section{Results}

Total 413 patients were included in the study. The mean age was 56.98 [12.52] years. Among them $74 \%$ [ $n=306]$ were male and $26 \%$ [ $n=107]$ were female. The male to female ratio was 2.8:1. Majority of patients were in age group of 41 to 60 years $[n=208,50.36 \%] .76 .5 \%$ patients were from rural area $[\mathrm{n}=316]$ with rural to urban ratio was 3.25:1. Among all patients approximately $42 \%$ did not have formal primary schooling [ $\mathrm{n}=173$ ]. Ambulance services were used by only $54.2 \%$ [n=
224]. In $85.7 \%$ patients [ $n=354]$ chest pain was the first symptom. 54\% [n=222] developed first symptoms during day time. While $22 \%$ patients $[n=90]$ developed first symptom early in the morning

The mean symptom to door time was 723.89 [SD 688.] minutes (12 hours 3 minutes). A delay of $>$ 12 hours were seen in $36 \%$ [ $n=149]$ patients. Only $3 \%$ patients $[n=13]$ arrived within one hour of onset of symptoms while $9.7 \%$ patients $[n=40]$ arrived within 1 to 3hours, $24.5 \%$ patients $[\mathrm{n}=101]$ arrived within 3 to 6 hours and $26.6 \%$ patients [n=110] arrived within 6 to 12 hours of onset of symptoms.

\section{Figure 1}

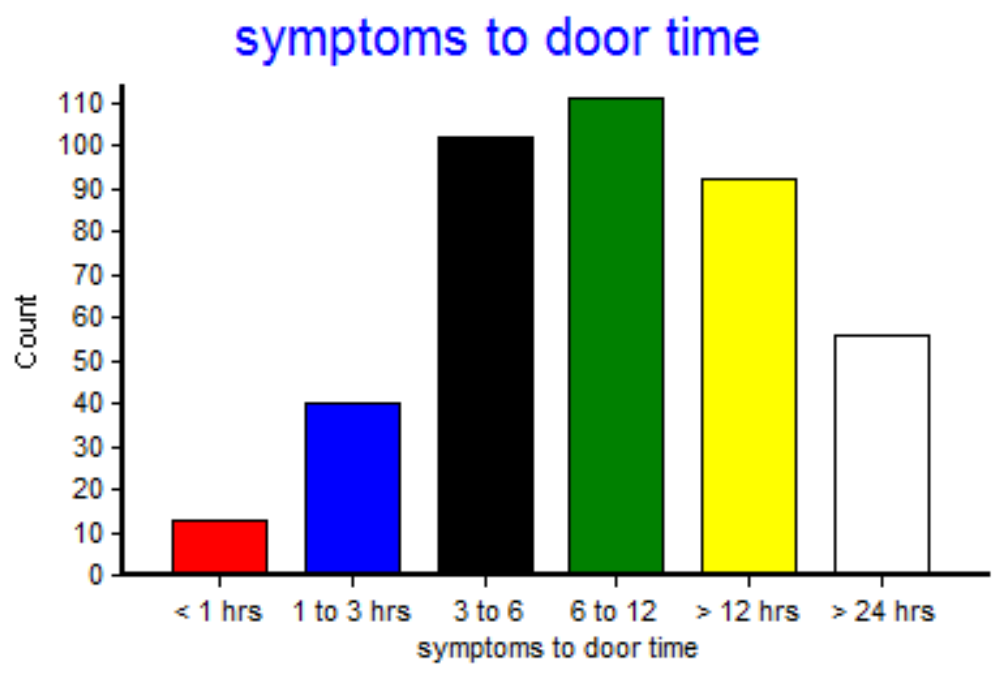

EpiData Analysis Graph

Table 1

\begin{tabular}{|l|c|c|c|c|}
\hline Observations & Numbers & $\begin{array}{c}\text { Thrombolysis group } \\
\mathrm{n}=215\end{array}$ & $\begin{array}{c}\text { Non thrombolysis group } \\
\mathrm{n}=198\end{array}$ & $\mathrm{P}$ value \\
\hline Male & 306 & $170[55.6 \%]$ & $136[44.4 \%]$ & 0.016 \\
\hline Urban residence & $97[23.5 \%]$ & $61[62.9 \%]$ & $36[37.1 \%]$ & 0.014 \\
\hline Ambulance services used & $224[54.2 \%]$ & $159[71 \%]$ & $65[29 \%]$ & 0.000 \\
\hline $\begin{array}{l}\text { Symptoms to door time in } \\
\text { minutes [mean, SD] }\end{array}$ & 413 & $402[263.6]$ & $1073.4[825]$ & 0.000 \\
\hline Door to ECG time in minutes & 413 & $10.25[5.67]$ & $10.75[5.62]$ & 0.20 \\
\hline door to decision time in minutes & 413 & $20.21[11.46]$ & $20.83[10]$ & 0.55 \\
\hline
\end{tabular}

$64.57 \%$ patients $(n=257)$ neglected their initial symptoms. It was the most common cause of prehospital delay followed by unavailability of transportation $[\mathrm{n}=71 ;(17.83 \%)]$. Late first consultation was taken by 58 [14.7\%] patients. $3 \%$ of patients $[\mathrm{n}=12]$ had pre-hospital delay either due to lack of ECG in outside hospital or due to missed diagnosis in outside hospital. 
Table 2 Prehospital factors

\begin{tabular}{|l|c|c|c|}
\hline Pre hospital delay factors & Total $\mathrm{n}=398$ & Thrombolysis group $\mathrm{n}=204$ & Non Thrombolysis group $\mathrm{n}=194$ \\
\hline Neglected symptoms & $257[64.57 \%]$ & $92[45.09 \%]$ & $165[85.05 \%]$ \\
\hline Late consultation & $58[14.7 \%]$ & $44[21.56 \%]$ & $14[7.21 \%]$ \\
\hline Lack of transport & $71[17.83 \%]$ & $60[29.41 \%]$ & $1[0.51 \%]$ \\
\hline $\begin{array}{l}\text { No ECG availability in } \\
\text { outside hospital }\end{array}$ & $3[0.75 \%]$ & $2[0.98 \%]$ & $3[1.54 \%]$ \\
\hline $\begin{array}{l}\text { Missed diagnosis in } \\
\text { outside hospital }\end{array}$ & $9[2.26 \%]$ & $6[2.94 \%]$ & \\
\hline
\end{tabular}

Among in-hospital delay factors $78 \%$ patients had delay due to delay in first ECG. The delay is said to occur if first ECG is taken after 10 minutes of arrival. Atypical symptoms in $15 \%$ and atypical ECG in $7 \%$ contributed in in-hospital delay. Mean door to ECG time is 10.49 min [SD 5.64] with minimum time noted is 2 minutes and maximum time is 45 minutes.
Door to decision time include ECG interpretation and starting of thrombolytic therapy after cardiology consultation. Mean door to decision was 20.51 [SD 10.79] minutes.

Table 3 In hospital factors

\begin{tabular}{|l|c|c|c|}
\hline In hospital delay factors & $\begin{array}{c}\text { Total } \\
(\mathrm{n}=100)\end{array}$ & Thrombolysis group & Non Thrombolysis group \\
\hline Atypical symptoms & 15 & $4[26.7 \%]$ & $11[73.3 \%]$ \\
\hline Delay in ECG & 78 & $46[59 \%]$ & $32[41 \%]$ \\
\hline Atypical ECG & 7 & $4[57.1 \%]$ & $3[42.9 \%]$ \\
\hline
\end{tabular}

Mean door to needle time is 35.84 minutes. The minimum and maximum time noted is 10 minutes and 120 minutes. $56 \%$ patients $[n=120]$ received thrombolysis within 30 minutes

The mean symptom to needle time is 7 hours 18 minutes. There is absolute difference of 31 minutes between males and females.

Typical symptoms like chest pain, sweating radiation of pain and palpitation are present in $96.9 \%, 76.5 \%, 62.2 \%$, and $40.4 \%$ respectively. While atypical symptoms like dyspnea, vomiting, epigastric pain, dizziness and nausea are present in $43.6 \%, 13.1 \%, \quad 10.9 \%, \quad 8.7 \%$ and $7.3 \%$ respectively.

Risk factors: Smoking was present in 54.2\% patients followed by BMI > 25 [42.43\%]. Diabetes is noted in $37.3 \%$ while hypertension is present in $29.3 \%$ patients.

Among 413 patients $52.1 \%$ patients [n=215] received thrombolysis for STEMI. Among 198 patients [47.9\%] who did not receive thrombolysis and received only medical treatment, the main contraindications were late presentation > 12 hours in $61 \%$ patients [ $n=121] .24$ elderly patients [age > 75 years] did not receive thrombolysis. And 4 patients had recent stroke. 60 patients (30.30\%) came within 12 hours but did not get thrombolysis. Among them in 25 patients chest pain was stopped or decreased significantly; 16 patients had cardiac arrest or prolonged CPR; 13 patients were thrombolysed for AMI within past 1 year. One patient had bleeding diabetic foot ulcer. 5 patients refused thrombolysis.

In Bivariate analysis of patients characteristics and thrombolysis treatment received; male gender, urban residence, use of ambulance services are statistically significant factors $(\mathrm{p}<0.05)$.

Whereas door to decision time which includes first ECG interpretation by ED resident doctor and consultation time with cardiologist for possible primary PCI was found to be statistically non significant. $(p=0.55)$ 


\section{Discussion}

In this current study majority of the subjects were males $[\mathrm{n}=306(74 \%)]$ with male to female ratio of 2.8:1 and predominantly from rural areas $(76.5 \%)$. The mean age was 57 years [SD 12.52] and approximately $40 \%$ are having no formal education. This distribution of the background variables were comparable in an Indian study done by Mohanan et al. in Kerala in which around $57 \%$ of the participants were in age group of 5070 years, majority were males $(77.3 \%)$ and $22.5 \%$ had no education in STEMI group. ${ }^{8}$

Age is an independent determinant found out in our study, older the age less likely to receive thrombolysis which is consistant finding in a study conducted by Brass et al. ${ }^{9}$

There is significant association between male gender, urban area and use of ambulance services with thrombolysis as a treatment modality received. Kendall et al reported that female gender is a determinant of prolonged pre-hospital delay. ${ }^{10}$ Prasantha et al. in Lucknow found, rural residence, literacy status, socio economic class, having BPL card and medical insurance are significantly $(p<0.05)$ associated with delay. ${ }^{11}$ Berger et al reported factors causing delay were old age, female gender, patients with diabetes, patients in shock and less marked ST elevation. ${ }^{12}$ while a study by Farshidi et al. showed age and gender were not found to be related with the prehospital delay time. ${ }^{13}$

Patients residing in urban areas $(\mathrm{p}=0.01)$ and who used ambulance services $(\mathrm{p}=0.000)$ for transport, arrived significantly earlier. Previous studies done by Matthews et al. in Boston and Hong et al. in tertiary hospital in Asia also reported that the use of ambulance reduced the delay. ${ }^{14-15}$ while Venkatachelam et al found out that Gender, age, literacy, mode of transport and past history of MI were not significant factors for pre-hospital delay. ${ }^{16} 46 \%$ of our patients came by private or public transports other than ambulance similar fact was seen in study by Lee et all in Korea where corresponding figure is $34 \% .^{17}$

Typical first symptom like chest pain was associated with early arrival as compared atypical symptoms. Jehangir et al found out that lack of knowledge of symptoms was associated with significant delay. ${ }^{18}$

The median door to first ECG time was 10 minutes [inter quartile range $8-10$ minutes] which is as proposed by AHA/ACC guidelines. ${ }^{19}$ Comparable results were found in study by Huynh et al in Canada AMI-QUEBEC study where median door to ECG time was 12 min for patients who came during regular working hours and 13 minutes who came outside regular hours. ${ }^{20}$

The mean door to needle time was 35.8 [SD18.6] minutes in this study. Thrombolytic therapy was started within the recommended 30 minutes for $56 \%$ of the patients. Similarly an ACS registry from Kerala reported that about $68 \%$ of the patients received thrombolysis within 30 minutes. ${ }^{21}$ While study conducted by Masurkar et al. in Mumbai in 2005 and Zed et al. in Riyadh in 2004 reported door to needle time of less than 30 minutes in $54.28 \%$ and $24.2 \%$ patients respectively. ${ }^{22-23}$

\section{Table 4}

\begin{tabular}{|l|c|c|c|}
\hline Door to needle time & No of patients [\%] & & \\
\hline & Present study $\mathrm{n}=215$ & Masurkar et al $\mathrm{n}=35$ & Zed et al $\mathrm{n}=140$ \\
\hline Mean door to needle time [SD] & $35.8[18.6]$ & 45.25 & 58 \\
\hline$<30$ minutes & $120[56 \%]$ & $19[54.28 \%]$ & $34[24.2 \%]$ \\
\hline $30-60$ minutes & $83[39 \%]$ & $10[28.57 \%]$ & $65[46.3 \%]$ \\
\hline$>60$ minutes & $12[6 \%]$ & $6[17.14 \%]$ & $41[29.3 \%]$ \\
\hline
\end{tabular}

Pre hospital delay factors in current study were neglected symptoms, female gender, rural residence. These were comparable with studies done in India ${ }^{11}$ Iran $^{13}$, Kashan ${ }^{24}$ and Salvador ${ }^{25}$.
The delay of $>12$ hours were seen in approx $36 \%$ [ $\mathrm{n}=149]$ patients while 63\% [n=259] patients came after 6 hours of symptom onset. The prehospital delay of $>6$ hours were reported in $41 \%$ 
patients in a study done by Mohanan et al in 2013 in Kerala. ${ }^{21}$ But much lesser median delay times were reported from Iran (2.6 hours) by Alishahi Tabriz et $\mathrm{al}^{25}$ and Beijing (2.3 hours) by Song li et al. $^{26}$

\section{Table 5}

\begin{tabular}{|c|c|c|c|}
\hline Risk factor & $\begin{array}{c}\text { current study in India } \\
2016 \mathrm{n}=413 \\
\end{array}$ & $\begin{array}{c}\text { Mohanan et al. }{ }^{21} \text { in India } \\
2013 \mathrm{n}=9569\end{array}$ & $\begin{array}{c}\text { Song et al. }{ }^{27} \text { in Beijing, } \\
\text { China } 2010 n=799\end{array}$ \\
\hline Hypertension & $121[29.3 \%]$ & $5315(55.5 \%)$ & $252[54.2 \%]$ \\
\hline Diabetes & $154[37.3 \%]$ & $3314(34.6 \%)$ & $98[21.1 \%]$ \\
\hline Smoking & $224[54.2 \%]$ & $3376(35.3 \%)$ & $243[52.3 \%]$ \\
\hline Known CAD & $38[9.2 \%]$ & $1257(13.1 \%)$ & $164[35.3 \%]$ \\
\hline $\mathrm{BMI}>25$ & $171[42.43 \%]$ & & $211[45.4 \%]$ \\
\hline
\end{tabular}

\section{Limitations}

The study population does not exactly represent STEMI population as patients who were taken for PCI or who is already thrombolysed in outside hospital are excluded. Being a single center study, the results cannot be generalized to the whole population and needs replications by large multicenter studies.

\section{Conclusion}

ACS/STEMI is a major problem in south India. Symptom to door time is unacceptably high in the study population. Only $52.1 \%$ patients received thrombolytic treatment in current study and among them only 56\% received it within 30 minutes which below the standards given by AHA/ACC.

$36 \%$ patients have reached hospital after 12 hours of symptoms indicated significant pre-hospital delay. The mean door to ECG time [10.49 minutes] and mean door to needle time [35.84minutes] are closer to recommended time given by AHA/ ACC.

The significant delay was due to pre-hospital factors which can be minimised by public education, awareness about CAD, use of ambulance services and good pre hospital care system. In-hospital delay factors can be minimised by good triage system and efficient teamwork.

Early recognition of symptoms, early contact with Emergency Department and early thrombolysis will have better outcome in STEMI patients.
In current study risk factors such as hypertension [29.3\%], diabetes [37.3\%], smoking [54.2\%], CAD [9.2\%] and BMI > 25 [42.43\%] were noted and were comparable with studies done by Mohanan et al. [2013 in Kerala India] ${ }^{21}$ and Song et al. [2010 in Beijing China ${ }^{27}$ 
[GRACE]). Am J Cardiol. 2009 ; 103(5):598-603.

7. Henriksson C, Larsson M, Arnetz Jet al. Knowledge and attitudes toward seeking medical care for AMI-symptoms. Int J Cardiol. 2011; 147(2):224-7.

8. Eagle KA, Nallamothu BK, Mehta RH, et al. Trends in acute reperfusion therapy for ST-segment elevation myocardial infarction from 1999 to 2006: we are getting better but we have got a long way to go. Eur Heart J. 2008;29(5):609-17.

9. Brass LM, Lichtman JH, Wang Y et al. Intracranial hemorrhage associated with thrombolytic therapy for elderly patients with acute myocardial infarction: results from the Cooperative Cardiovascular Project. Stroke J Cereb Circ. 2000;31(8):1802-11.

10. Kendall H, Marley A, Patel JVet al. Hospital delay in South Asian patients with acute ST-elevation myocardial infarction in the UK. Eur J Prev Cardiol. 2013;20(5):737-42.

11. B P, Idris MZ, Ahmad N,etal. Determinants of Prehospital Delay among Patients Attending Cardiac Emergency with Acute Chest Pain of Cardiac Origin in Lucknow District. 2013 Available from: https://core.ac.uk/display/27615707

12. Berger AK, Radford MJ, Krumholz HM. Factors associated with delay in reperfusion therapy in elderly patients with acute myocardial infarction: Analysis of the Cooperative Cardiovascular Project. Am Heart J. 2000 1;139(6):985-92.

13. Farshidi H, Rahimi S, Abdi A,et al. Factors Associated With Pre-hospital Delay in Patients With Acute Myocardial Infarction. Iran Red Crescent Med J. 2013;15(4):312-6.

14. Mathews R, Peterson ED, Li S, et al. Use of Emergency Medical Service Transport Among Patients With ST-SegmentElevation Myocardial InfarctionClinical
Perspective.

Circulation.

2011 12;124(2):154-63.

15. Hong CC, Sultana P, Wong ASL,et al. Prehospital delay in patients presenting with acute ST-elevation myocardial infarction: Eur $\mathrm{J}$ Emerg Med. 2011;18(5):268-71.

16. Venkatachelam R, Adilakshmi B, Ram Manohar T,et al. Factors affecting time to arrival in hospital among patients with acute myocardial infarction (MI). J Sci Innov Res. 2015;4(2):109-14.

17. Lee MR, Yun KH, Kim DH, et al. Factors Related to Pre-hospital Delay in Korean Patients with ST-segment Elevation Myocardial Infarction: A Data from the Province of Jeonbuk Regional Cardiovascular Center. J Lipid Atheroscler. 2016;5(1):21.

18. Jehangir W, Daood MS, Khan M,et al. Evaluation of the door-to-needle time in patients undergoing fibrinolytic therapy after acute myocardial infarction. Pak J Physiol. 2009;5(2):38

19. O'Gara PT, Kushner FG, Ascheim DD, et al. 2013 ACCF/AHA Guideline for the Management of ST-Elevation Myocardial InfarctionA Report of the American College of Cardiology

Foundation/American Heart Association Task Force on Practice Guidelines. J Am Coll Cardiol. 2013 29;61(4):e78-140.

20. Huynh T, O'Loughlin J, Joseph Let al. Delays to reperfusion therapy in acute STsegment elevation myocardial infarction: results from the AMI-QUEBEC Study. Can Med Assoc J. 2006 5;175(12):152732.

21. Mohanan PP, Mathew R, Harikrishnan S, et al. Presentation, management, and outcomes of 25748 acute coronary syndrome admissions in Kerala, India: results from the Kerala ACS Registry. Eur Heart J. 2013;34(2):121-9. 
22. Masurkar V, Kapadia F, Shirwadkar C,et al. Evaluation of the door-to-needle time for fibrinolytic administration for acute myocardial infarction. Indian $\mathrm{J}$ Crit Care Med. 2005;9(3):137.

23. Zed PJ, Abu-Laban RB, Cadieu TM,et al. Fibrinolytic administration for acute myocardial infarction in a tertiary ED: factors associated with an increased doorto-needle time. Am J Emerg Med. 2004;22(3):192-6.

24. Saberi F, Adib-Hajbaghery M, Zohrehea J. Predictors of Prehospital Delay in Patients With Acute Myocardial Infarction in Kashan City. Nurs Midwifery Stud [Internet]. 2014 Dec;3(4). Available from: http://www.ncbi.nlm.nih.gov/pmc/articles/ PMC4348727/

25. Mussi FC, Mendes AS, Queiroz TL de,et al. Pre-hospital delay in acute myocardial infarction: judgement of symptoms and resistance to pain. Rev Assoc Médica Bras. 2014;60(1):63-9.

26. Tabriz A, Sohrabi M-R, Kiapour N,et al. Factors Associated with Delay in Thrombolytic Therapy in Patients with STElevation Myocardial Infarction. J Tehran Heart Cent. 2012;7(2):65-71.

27. Song L, Yan H, Hu D. Patients with acute myocardial infarction using ambulance or private transport to reach definitive care: which mode is quicker? Intern Med J. 2010;40(2):112-6. 